20

\title{
К вопросу об эффективности плазмонной фототермической терапии экспериментальных опухолей
}

\author{
() А.Б. Бучарская ${ }^{1}$, Г.Н. Маслякова ${ }^{1}$, М.Л. Чехонацкая ${ }^{1}$, Н.Б. Захарова ${ }^{1}$, Г.С. Терентюк $^{1}$, Н.А. Наволокин ${ }^{1}$, \\ Б.Н. Хлебцов ${ }^{2}$, Н.Г. Хлебцов ${ }^{2}$, В.Д. Генин ${ }^{3,4}$, А.Н. Башкатов ${ }^{3,4}$, Э.А. Генина ${ }^{3,4}$, В.В. Тучин ${ }^{3,4,5}$ \\ ${ }^{1}$ Саратовский государственный медицинский университет им. В.И. Разумовского, \\ 410012 Саратов, Россия \\ ${ }^{2}$ Институт биохимии и физиологии растений и микроорганизмов РАН, \\ 410012 Саратов, Россия \\ ${ }^{3}$ Саратовский национальный исследовательский государственный университет им. Н.Г. Чернышевского, \\ 410012 Саратов, Россия \\ ${ }^{4}$ Национальный исследовательский Томский государственный университет, \\ 634050 Томск, Россия \\ ${ }^{5}$ Институт проблем точной механики и управления РАН, \\ 410028 Саратов, Россия \\ e-mail: allaalla_72@mail.ru
}

Поступила в редакцию 11.12.2019 г.

В окончательной редакции 01.02.2020 г.

Принята к публикации 28.02.2020 г.

Целью исследования было изучение прогностических факторов эффективности плазмонной фототермической терапии (ПФТ) у крыс с перевитым раком печени на основе оценки степени васкуляризации опухолей. До начала какого-либо воздействия крысам с перевитым раком печени РС-1 проводили допплерографическое исследование для оценки степени васкуляризации перевитых опухолей. Половину животных с перевитыми опухолями выводили из эксперимента после допплерографии для определения методом иммуноферментного анализа содержания сосудистых факторов в сыворотке крови и иммуногистохимическим методом в ткани опухоли. После трехкратного внутривенного введения покрытых полиэтиленгликолем золотых наностержней (3НС) в дозировке $0.4 \mathrm{mg} / \mathrm{ml}$ перевитые опухоли облучали чрескожно инфракрасным лазерным излучением на длине волны $808 \mathrm{~nm}$ и проводили термографию локального нагрева опухоли. Через $24 \mathrm{~h}$ животных выводили из эксперимента и забирали образцы опухолевой ткани для гистологического исследования. Установлено, что накопление золота в опухолевой ткани и эффективность ПФТ при многократном внутривенном введении ЗНС определяются наличием сформированной сосудистой сети в опухоли.

Ключевые слова: золотые наностержни, ИК лазерное излучение, внутривенное введение, допплерографическое исследование, васкулоэндотелиальный фактор роста, морфология.

DOI: $10.21883 / O S .2020 .06 .49419 .34-20$

\section{Введение}

В последние десятилетия на стыке биомедицинских наук и оптических нанотехнологий интенсивно развивается новое научное направление - тераностика. Тераностика предполагает разработку новых наноматериалов, обладающих при действии лазерного излучения как диагностическими, так и терапевтическими свойствами [1]. Среди потенциальных агентов для тераностики особое место занимают золотые наночастицы (ЗНЧ), эффективно нагреваемые излучением инфракрасных лазеров. Перспективность применения ЗНЧ определяется их нетоксичностью и наличием плазмонного резонанса в ближней инфракрасной области (БИК) [2,3]. Они могут использоваться для оптической визуализации опухолевых клеток [4], в качестве носителей таргетной доставки лекарственных веществ [5] и термосенсибилизаторов для плазмонной фототермической терапии (ПФТ) [6].
Особенности строения сосудистой сети опухоли обусловливают возможность пассивной доставки и накопления наночастиц в опухоли при внутривенном введении за счет так называемого эффекта „повышенной проницаемости и задержания“" [7]. Активность ангиогенеза в опухолевой ткани зависит от баланса ряда стимулирующих или ингибирующих факторов. Ключевой сигнальной системой, которая регулирует процессы васкуляризации опухоли, являются факторы роста эндотелия сосудов VEGF и их рецепторы [8].

Для эффективного проведения ПФТ опухолей с использованием золотых наночастиц в качестве термосенсибилизаторов необходимо достаточное накопление наночастиц в опухоли, что, вероятнее всего, зависит от степени васкуляризации опухоли, а также оптимальных временных интервалов и дозировок наночастиц при внутривенном введении. В связи с этим целью настоящего исследования являлось исследование эффективности ПФТ у крыс с перевитым раком печени для разработки 
прогностических факторов на основе оценки степени васкуляризации опухолей.

\section{Материалы и методы}

Экспериментальное исследование проводили в Центре коллективного пользования СГМУ им. В.И. Разумовского на 24 белых беспородных крысах-самцах согласно международным этическим нормам Европейской конвенции защиты позвоночных животных для экспериментальных и других научных целей (Страсбург, 1986), а также в соответствии с рекомендациями комитета по этике ФГБОУ ВО Саратовского ГМУ им. В.И. Разумовского Минздрава РФ (протокол № 6 от 06.02.2018г.). Все применимые международные, национальные и/или институциональные принципы ухода и использования животных были соблюдены.

Альвеолярный рак печени РC1 имплантировали крысам подкожно в области лопатки по $0.5 \mathrm{ml} 25 \%$ опухолевой взвеси в растворе Хэнкса. При достижении опухолями объема $\geq 3 \mathrm{~cm}^{3}$ до начала какого-либо воздействия крысам проводили допплерографическое исследование перевитых опухолей с использованием ультразвукового аппарата Voluson E8 Expert (GE Healthcare, USA) на частоте $7.2 \mathrm{MHz}$ в соответствии со стандартными критериями. Для оценки степени васкуляризации опухолей проводили исследование в режиме энергетической допплерографии и использовали программное обеспечение VOCAL (virtual organ computer aided analysis) c определением объема опухоли и вычислением индекса васкуляризации (VI), характеризующего плотность микрососудов капиллярного типа в опухоли [9].

Половину животных с перевитыми опухолями после допплерографии выводили из эксперимента для определения содержания сосудистых факторов в сыворотке крови - васкулоэндотелиального фактора роста VEGF-C (Bender MedSystems, Austria) и рецептора васкулоэндотелиального фактора роста VEGFR1 (RayBiotech, Inc., USA) методом иммуноферментного анализа (ИФА). В качестве показателей контрольной группы использовали показатели сосудистых факторов в сыворотке крови у 12 здоровых интактных крыс-самцов.

Для гистологического исследования образцы тканей опухоли фиксировали в $10 \%$ растворе формалина, подвергали стандартной спиртовой проводке и окрашивали гематоксилином и эозином. Для морфометрического исследования микрососудистой плотности в ткани опухоли использовали систему анализа цифровых изображений Микровизора медицинского $\mu$ Vizo-103 (ЛОМО, СанктПетербург). Для определения микрососудистой плотности в опухоли вычисляли суммарную площадь сосудов в поле зрения гистологического препарата, подсчет проводился в 10 полях зрения при увеличении 246.4. Иммуногистохимическое окрашивание ткани опухоли проводили с антителами к васкулоэндотелиальному фактору роста VEGFA (Abcam, UK) с использованием безбиотиновой системы детектирования REVEAL Polyvalent HRP-DAB Detection System (Spring Bioscience, USA).

Для внутривенного введения использовали покрытые полиэтиленгликолем (ПЭГ) золотые наностержни, синтезированные по методике зародышевого роста в лаборатории нанобиотехнологиии ИБФРМ РАН [10]. Геометрические параметры ЗНС определяли по изображениям, полученным методом трансмиссионной электронной микроскопии на микроскопе Libra-120 (Carl Zeiss, Germany), длина и диаметр стержней составляли $41 \pm 8 \mathrm{~nm}$ и $10 \pm 2 \mathrm{~nm}$ соответственно; концентрация золота $400 \mu \mathrm{g} / \mathrm{ml}$ соответствовала оптической плотности 20 при $810 \mathrm{~nm}$. Оставшимся в эксперименте крысам проводили трехкратное внутривенное введение покрытых ПЭГ ЗНС по разработанному нами ранее протоколу $[11]$ и через сутки после последнего введения проводили ПФТ с использованием БИК лазера с длиной волны $808 \mathrm{~nm}$ и плотностью мощности излучения $2.3 \mathrm{~W} / \mathrm{cm}^{2}$. Термографию локального нагрева опухоли проводили с использованием тепловизора IRYSYS 4010 (UK). Животных выводили из эксперимента сразу после проведения ПФТ, забирали ткань опухоли для определения содержания золота методом атомно-адсорбционной спектроскопии (ААС) и гистологического исследования. При определении содержания золота в опухоли методом ААС проба составляла $1 \mathrm{~g}$ навески ткани для исследований на спектрофотометре Dual Atomizer Zeeman AA iCE 3500 (Thermo Scientific Inc., USA) в Центре коллективного пользования „Симбиоз“ ИБФРМ РАН. В качестве показателей контрольной группы использовали показатели содержания золота в печени и селезенке у 6 здоровых интактных крыссамцов при трехкратном внутривенном введении той же дозировки ЗНС.

Статистическую обработку полученных данных выполняли с помощью пакета статистических программ SSPS-13.0. Для проверки нормальности распределения значений в выборке использовали тест КолмогороваСмирнова. При нормальном распределении вычисляли среднее и среднее квадратичное отклонение, для сравнения полученных показателей использовали критерий Крамера-Уэлча. При отличии распределения от нормального вычисляли медиану и квартили, показатель достоверности различий $(p)$ определяли с использованием непараметрического критерия Манна-Уитни. Для оценки взаимосвязи показателей был использован коэффициент корреляции Пирсона.

\section{Результаты исследований}

При трехмерном допплерографическом исследовании перевитые опухоли визуализировались как гипоэхогенные образования с неоднородной эхоструктурой, окруженные капсулой с ровными и четкими контурами. На периферии опухолей располагались крупные приносящие сосуды с равномерно окрашенным просветом, длина 

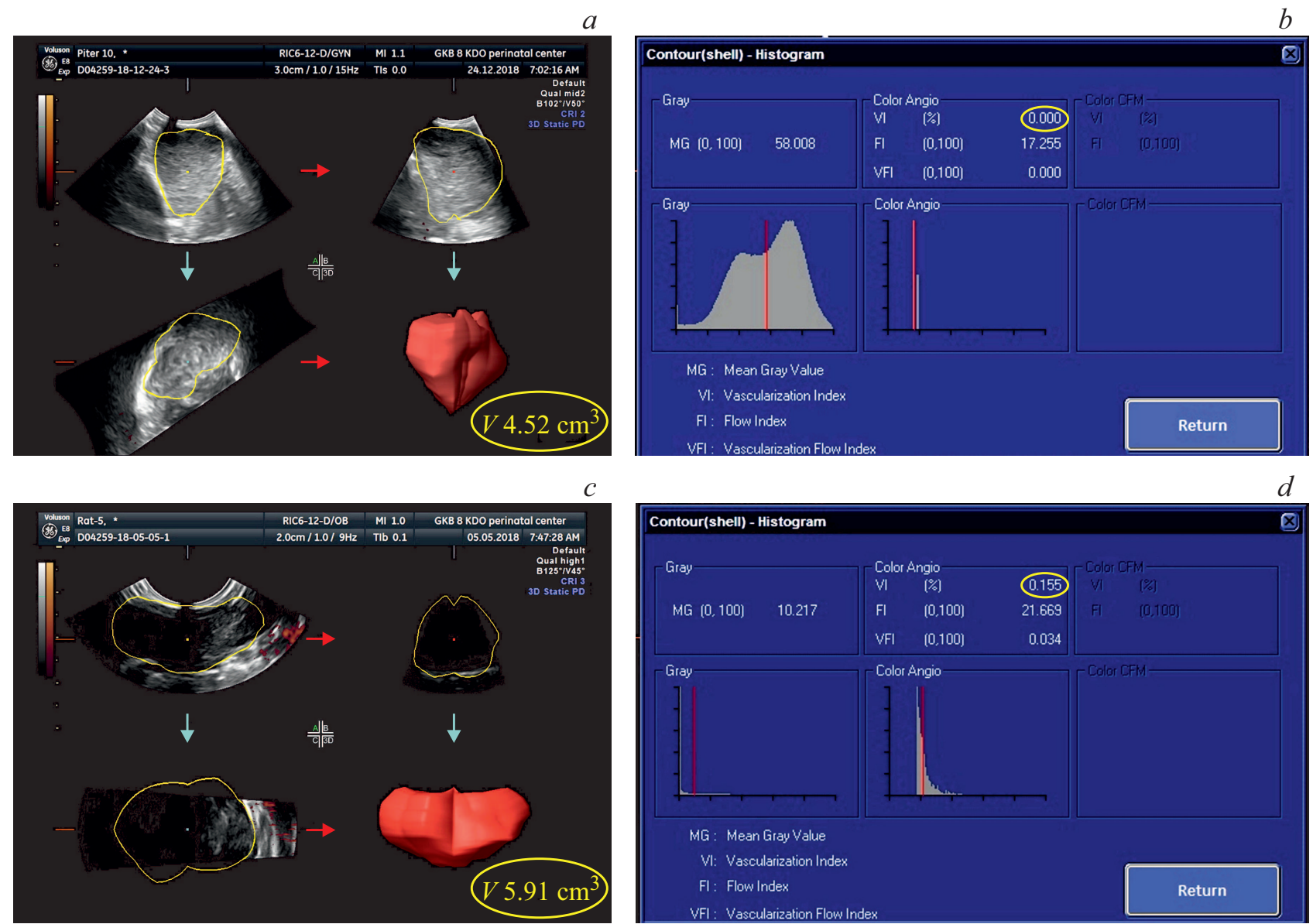

Рис. 1. Энергетическое допплерографическое исследование опухолей крыс. (a) Опухоль мало васкуляризирована, объем опухоли $V=4.52 \mathrm{~cm}^{3}$, индекс васкуляризации $V I=0 \% ;(c)$ Опухоль хорошо васкуляризирована, объем опухоли $V=5.91 \mathrm{~cm}^{3},(d)$ индекс васкуляризации $V I=0.155 \%$.

визуализируемых фрагментов сосудов различалась в зависимости от их локализации. В крупных сосудах, питающих опухоль, на одном и том же сроке после перевивки опухоли параметры кровотока в них значительно варьировали и характеризовались низким сосудистым сопротивлением и высокой скоростью кровотока. Эти различия были связаны с различной степенью васкуляризации опухолей.

При проведении энергетической допплерографии было установлено, что при достижении опухолью определенного объема (от $5 \mathrm{~cm}^{3}$ до $10 \mathrm{~cm}^{3}$ ) индекс васкуляризации возрастал с увеличением объема опухоли (рис. 1). При достижении объема опухоли свыше $10 \mathrm{~cm}^{3}$ и более индекс васкуляризации перевитых опухолей печени начинал снижаться. Возможно, что рост опухоли опережал рост сосудов, и из-за недостаточного кровоснабжения в ней развивались некротические изменения прежде всего в центральных ее отделах, что было в дальнейшем подтверждено данными гистологического исследования. По результатам допплерографического исследования крысы с перевитыми опухолями были разделены на 2 группы: с объемом опухоли менее $5 \mathrm{~cm}^{3}$ и свыше $5 \mathrm{~cm}^{3}$.
Методом ИФА было установлено, что показатели VEGFR1 были более высокими у крыс с небольшими, слабо васкуляризированными опухолями размером до $5 \mathrm{~cm}^{3}$ по сравнению с контрольной группой $(p=0.034)$ и крысами с крупными опухолями размером более $5 \mathrm{~cm}^{3}(p=0.008)$. До настоящего времени данные о биологической роли VEGFR1 в ангиогенезе достаточно противоречивы. VEGFR1 оказывает ингибирующее воздействие на эмбриональный ангиогенез, связываясь с VEGF-A и препятствуя связыванию его с проангиогенным фактором - рецептором VEGFR2, и стимулирующее воздействие на ангиогенез - во взрослом возрасте. Известно, что VEGFR1 экспрессируется не только в эндотелиальных клетках, но также в клетках макрофагального происхождения и способствует росту опухолей, метастазированию и воспалению [12]. Повышение уровня VEGFR1 в сыворотке у животных с небольшими опухолями может происходить в ответ на увеличение экспрессии VEGFA в растущих опухолях.

Показатели VEGF-C в сыворотке крови у крыс с крупными опухолями, размерами свыше $5 \mathrm{~cm}^{3}$, значительно превышали аналогичные показатели в контроль- 

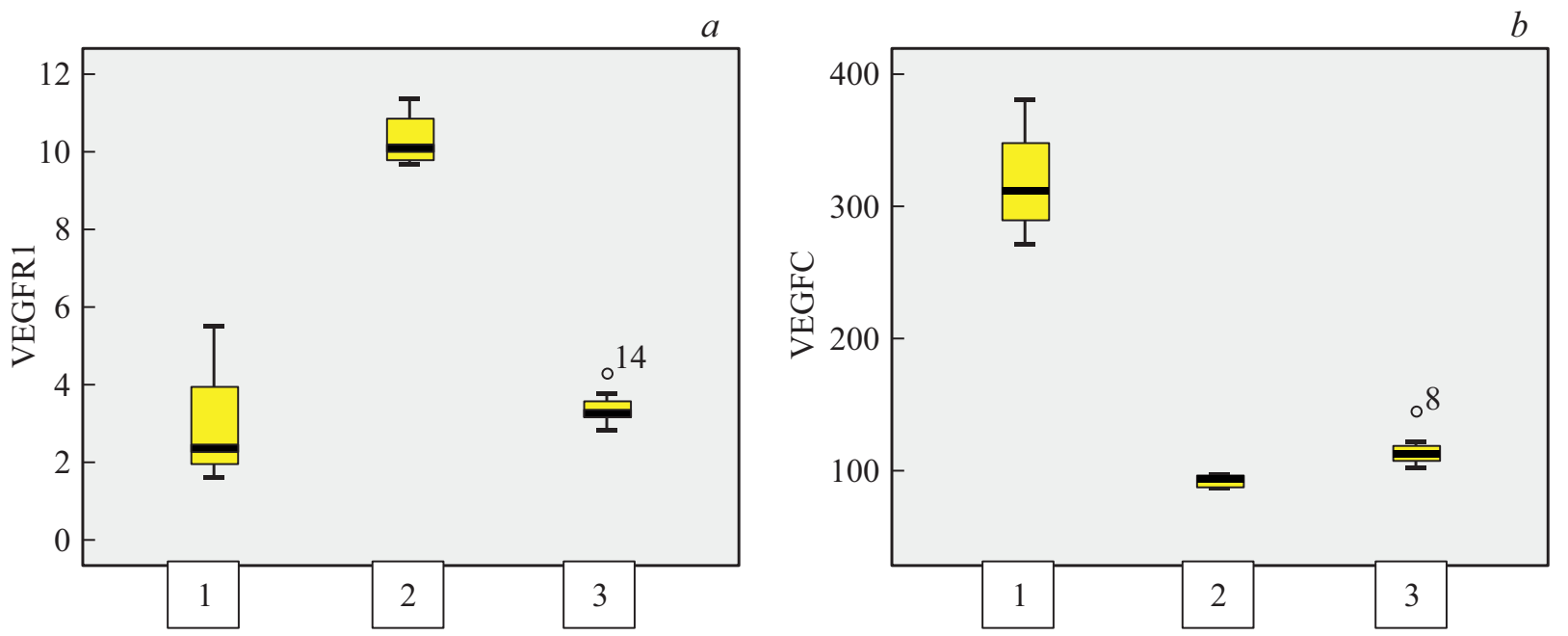

Рис. 2. Содержание сосудистых факторов в сыворотке крови у крыс с перевитыми опухолями. Графики „бокс-плот“ (a)

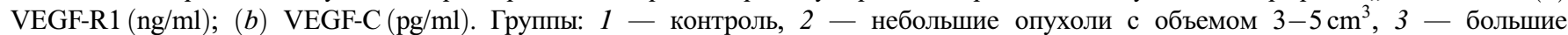
опухоли $\left(>5 \mathrm{~cm}^{3}\right)$.
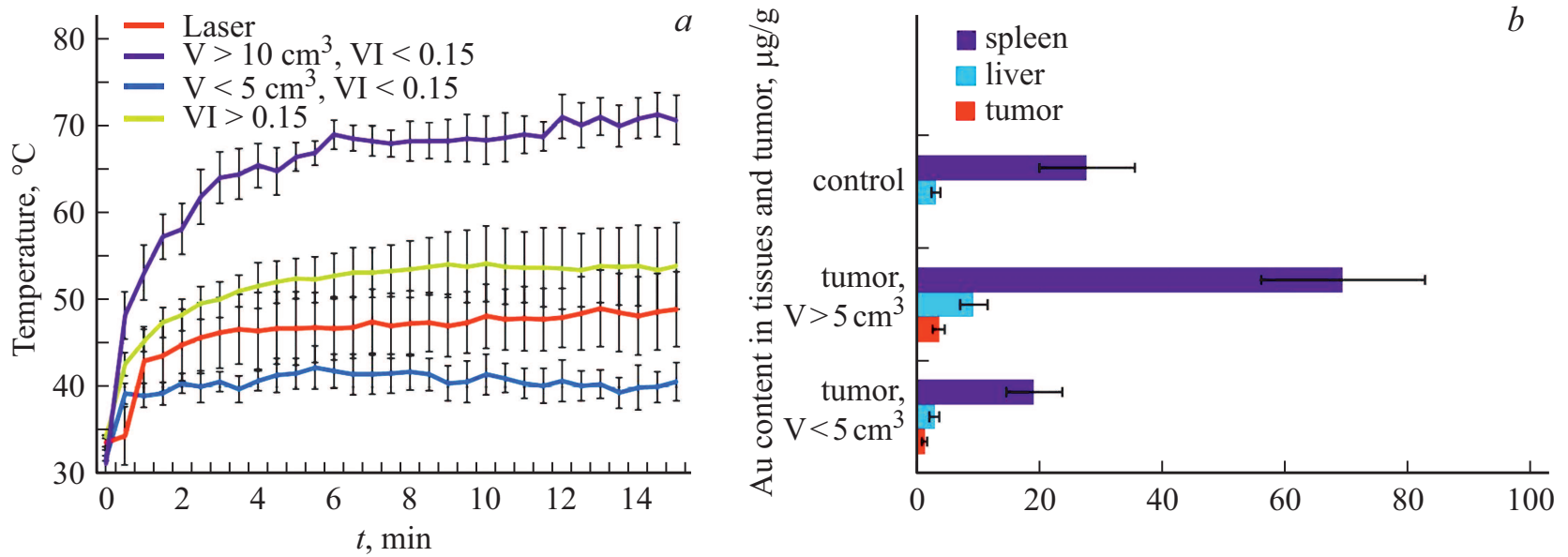

Рис. 3. (a) Термограммы перевитых опухолей при ПФТ. $(b)$ Содержание золота $(M \pm \sigma, \mu \mathrm{g} / \mathrm{g})$ в опухоли, печени и селезенке при трехкратном внутривенном введении ЗНС по данным ААС.

ной группе $(p=0.017)$ и у крыс с небольшими, слабо васкуляризированными опухолями размером до $5 \mathrm{~cm}^{3}$ $(p=0.008)$ (рис. $2, b)$. Известно, что васкулоэндотелиальный фактор роста VEGF-C стимулирует процессы лимфангиогенеза [8]. Повышение уровня VEGF-C у крыс, вероятно, свидетельствует об активации процессов лимфангиогенеза при дальнейшем росте опухолей.

Полученные нами при допплерографическом исследовании показатели васкуляризации опухолей сравнивали с морфометрическими параметрами микрососудистой плотности и данными о накоплении золота в опухоли при многократном внутривенном введении. Было установлено наличие положительной корреляционной зависимости между индексом васкуляризации и показателем микрососудистой плотности $(r=0.96$ при $p<0.01)$, что согласуется с данными других авторов [13].
При анализе показателей температуры локального нагрева опухоли (рис. 3,a) было установлено, что нужного подъема температуры для эффективного проведения ПФТ удавалось достичь только при значении индекса васкуляризации не менее 0.15. При проведении корреляционного анализа было установлено наличие зависимости между индексом васкуляризации и содержанием золота в опухоли при повторных внутривенных инъекциях ЗНС $(r=0.77$ при $p<0.01)$. У крыс с объемом опухоли свыше $5 \mathrm{~cm}^{3}$ и значениями индекса васкуляризации свыше 0.15 отмечалось повышение накопления золота в опухоли (рис. 3, $b$ ). Содержание золота в печени и селезенке у крыс с объемом опухоли менее $5 \mathrm{~cm}^{3}$ незначительно отличалось от аналогичных показателей у крыс в контрольной группе. Это согласуется с литературными данными по токсичности и биораспределению наночастиц золота [14]. Увеличение 

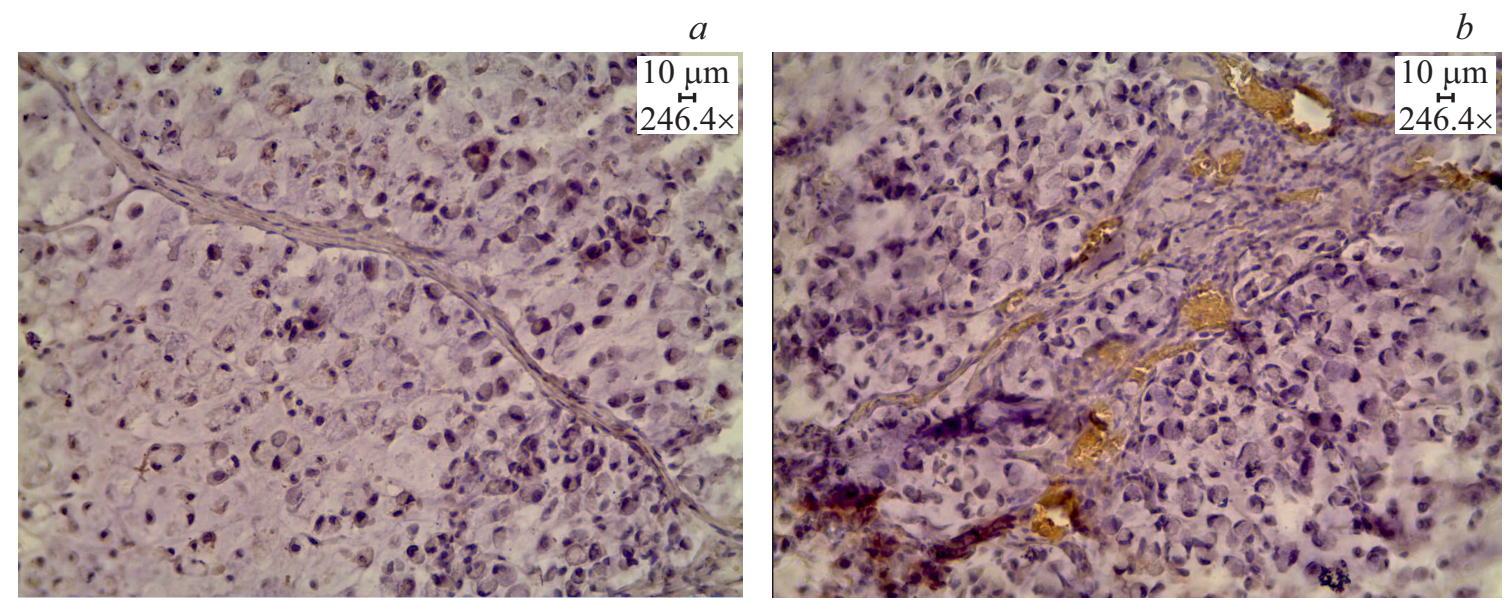

Рис. 4. Холангиокарцинома печени. Иммуногистохимическое окрашивание с антителом к VEGFA. х246. (a) Опухоль с низкой степенью васкуляризации $(V I=0.034)$. (b) Опухоль с высокой степенью васкуляризации $(V I=0.155)$.

накопления золота в печени и селезенке у крыс с объемом опухоли свыше $5 \mathrm{~cm}^{3}$ может быть связано с нарушениями детоксикационной функции печени и селезенки при воздействии растущей опухоли на организм.

В перевитых опухолях проводили иммуногистохимическое окрашивание с антителами к васкулоэндотелиальному фактору роста VEGFA. Известно, что белок VEGFA семейства VEGF стимулирует пролиферацию и миграцию эндотелиальных клеток, а также увеличивает проницаемость микрососудов [15].

Наши исследования показали, что в опухолях с высокими показателями индекса васкуляризации отмечалась более выраженная экспрессия васкулоэндотелиального фактора VEGFA (рис. 4, $a, b$ ). Эти результаты согласуются с данными исследования $Y$. Hori и соавторов [16], которые установили, что в опухолях с более высоким уровнем экспрессии VEGF наблюдалось большее накопление PEG-покрытых липосом за счет более выраженного EPR-эффекта проницаемости и задержания в опухолевых сосудах [16]. Следовательно, повышенная экспрессия VEGFA в опухолевой ткани свидетельствует об активации ангиогенеза и повышении проницаемости сосудов опухоли, что является необходимым условием для достаточного накопления наночастиц.

\section{Выводы}

Эффективное проведение противоопухолевой плазмонной фототермической терапии при многократном внутривенном введении покрытых полиэтиленгликолем золотых наностержней возможно при достаточном накоплении золотых наночастиц в опухолевой ткани. Это может быть достигнуто при наличии сформированной сосудистой сети в опухоли, о чем свидетельствует индекс васкуляризации опухоли не менее 0.15 .

Допплерографическое исследование может быть использовано для неинвазивной оценки степени васку- ляризации опухолевой ткани, что необходимо для оптимального выбора времени проведения внутривенных инъекций ЗНС перед ПФТ терапией.

Для выбранной плотности лазерного излучения $(808 \mathrm{~nm})$ на поверхности опухоли, равной $2.3 \mathrm{~W} / \mathrm{cm}^{2}$, достаточно было обеспечить экспозицию в 5-6 min для достижения температуры около $70^{\circ} \mathrm{C}$ и получения надежного терапевтического эффекта для опухолей с высокой степенью васкуляризации при значительном накоплении в них наночастиц за счет многократного внутривенного введения.

\section{Соблюдение этических стандартов}

Исследование проводили согласно международным этическим нормам Европейской конвенции защиты позвоночных животных для экспериментальных и других научных целей (Страсбург, 1986), а также в соответствии с рекомендациями комитета по этике ФГБОУ ВО Саратовского ГМУ им. В.И. Разумовского Минздрава РФ (протокол № 6 от 06.02.2018 г.). Все применимые международные, национальные и/или институциональные принципы ухода и использования животных были соблюдены.

\section{Финансирование работы}

Работа выполнена в рамках государственного задания Минздрава России „Молекулярные маркеры и золотые наночастицы: применение для целей тераностики в экспериментальной и клинической онкологии“ (№ государственной регистрации 0203042330329) и грантов РФФИ 18-52-7803 (Итал-т) и 19-32-90224. ВВТ был поддержан в рамках Программы фундаментальных исследований Президиума РАН № 32 „Наноструктуры: физика, химия, биология, основы технологий“ (подпрограмма „Нанобиотехнологии“, 2018-2020). 


\section{Конфликт интересов}

Авторы заявляют, что у них нет конфликта интересов.

\section{Список литературы}

[1] Courtine E., Cariou A., Mira J.P. // Crit Care Med. 2009. V. 37. P. S50-S58.

[2] Dykman L.A., Khlebtsov N.G. // Biochemistry (Moscow). 2016. V. 81. N 13. P. 1771-1789.

[3] Bucharskaya A., Maslyakova G., Terentyuk G., Yakunin A., Avetisyan Y., Bibikova O., Tuchina E., Khlebtsov B., Khlebtsov N., Tuchin V. // Int. J. Mol. Sci. 2016. V. 17. N 8. P. 1295. doi 10.3390/ijms17081295

[4] Park J., Estrada A., Sharp K., Sang K., Schwartz J.A., Smith D.K., Coleman C., Payne J.D., Korgel B.A., Dunn A.K., Tunnell J.W. // Opt. Express. 2008. N 16. P. 1590-1599. doi 10.1364/oe.16.001590

[5] Pérez-Herrero E., Fernández-Medarde A. // Eur. J. Pharm Biopharm. 2015. V. 93. P. 52-79. doi 10.1016/j.ejpb.2015.03.018

[6] Chen J., Glaus C., Laforest R., Zhang Q., Yang M., Gidding M., Welch M.J., Xia Y. // Small. 2010. V. 6. P. 811-817. doi 10.1002/smll.200902216

[7] Fang J., Nakamura H., Maeda H. // Adv. Drug. Deliv. Rev. 2011. V. 63(3):136-151. doi 10.1016/j.addr.2010.04.009

[8] Карамымева А.Ф. // Биохимия. 2008. Т. 73. № 7. C. $935-948$.

[9] Samsung Medison. Программа VOCAL - вычисление объемов структур (3D эхография). [Электронный ресурс]. Режим доступа: https:/www.medison.ru/tn/vocal.htm

[10] Khlebtsov B., Khanadeev V., Pylaev T., Khlebtsov N. // J. Phys. Chem. C. 2011. V. 115. N 14. P. 6317-6323. doi $10.1021 /$ jp2000078

[11] Bucharskaya A.B., Maslyakova G.N., Dikht N.I., Navolokin N.A., Terentyuk G.S., Bashkatov A.N., Genina E.A., Khlebtsov B.N., Khlebtsov .G., Tuchin V.V. // BioNanoScience. 2017. V. 7. N 1. P. 216-221. doi 10.1007/s12668-016-0320-z

[12] Shibuya M. // J. Biochem. Mol. Biol. 2006. V. 39(5). P. 469478.

[13] Yang W.T., Tse G., Lam P., Metreweli C., Chang J. // Ultrasound. Med. 2002. V. 21. P. 1227-1235.

[14] Khlebtsov N.G., Dykman L.A. // Chem. Soc. Rev. 2011. V. 40. P. 1647-1671. doi 10.1039/C0CS00018C

[15] Ferrara N. // Eur. Cytokine. Netw. 2009. V. 20. N 4. P. 158163. doi 1684/ecn.2009.0170

[16] Hori Y., Ito K., Hamamichi S., Ozawa Y., Matsui J., Umeda I.O., Fujii H. // Anticancer Res. 2017. V. 37. N 12. P. 6629-6638. doi 21873/anticanres.12120 